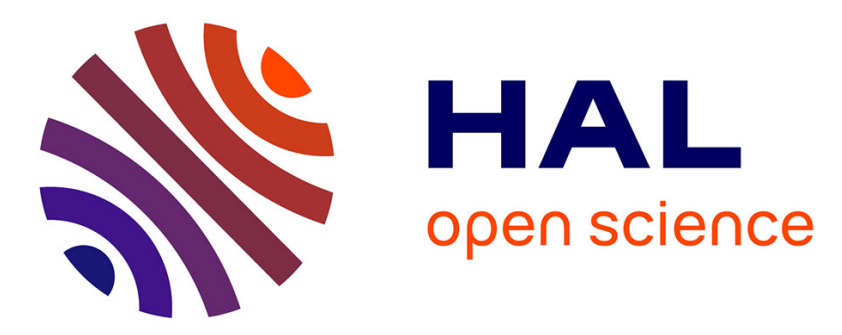

\title{
Two strain rate change tests for derivation of constitutive relationship of metals at very high rates of strain
}

\author{
J. Shioiri, K. Sakino, T. Santoh
}

\section{- To cite this version:}

J. Shioiri, K. Sakino, T. Santoh. Two strain rate change tests for derivation of constitutive relationship of metals at very high rates of strain. Journal de Physique IV Proceedings, 1994, 04 (C8), pp.C8-489C8-494. 10.1051/jp4:1994876 . jpa-00253437

\section{HAL Id: jpa-00253437 https://hal.science/jpa-00253437}

Submitted on 1 Jan 1994

HAL is a multi-disciplinary open access archive for the deposit and dissemination of scientific research documents, whether they are published or not. The documents may come from teaching and research institutions in France or abroad, or from public or private research centers.
L'archive ouverte pluridisciplinaire HAL, est destinée au dépôt et à la diffusion de documents scientifiques de niveau recherche, publiés ou non, émanant des établissements d'enseignement et de recherche français ou étrangers, des laboratoires publics ou privés. 


\title{
Two strain rate change tests for derivation of constitutive relationship of metals at very high rates of strain
}

\author{
J. Shioiri, K. Sakino and T. Santoh \\ College of Engineering, Hosei University, Koganei, Tokyo 184, Japan
}

\begin{abstract}
Résumê Deux types de test de changement de la vitesse de déformation ont êté effectués comme suit. Un test de réduction de la vitesse de déformation a été conduit sur l'aluminium, le cuivre, le fer et le niobium à des vitesses de déformation allant jusqu'à environ $20000 / \mathrm{s}$. Des mesures d'atténuation de l'onde ultrasonore superposée à la déformation plastique dynamique - test associant le changement de la vitesse de déformation à la perturbation de haute fréquence de celle-ci - ont été faites sur l'aluminium et le cuivre à des vitesses de déformation jusqu'â environ 10000/s. Les résultats de ces deux tests montrent que, l'histoire de la vitesse de deformation a un effet faible sur le stress de déformation.
\end{abstract}

\begin{abstract}
Two types of strain rate change test are conducted. The strain rate reduction test is made for aluminium, copper, iron and niobium at strain rates up to about $20000 / \mathrm{s}$. The attenuation measurement of the ultrasonic pulse superimposed upon the dynamic plastic deformation, a kind of strain rate change test with a high frequency perturbation of the strain rate, is made for aluminium and copper at strain rates up to about $10000 / \mathrm{s}$. Results show that, in the above high strain rate range, the effect of the strain rate history upon the strain rate dependency of the flow stress is small.
\end{abstract}

\section{INTRODUCTION}

The flow stress of metallic materials depends upon both the strain rate at the instant and the history of the strain rate. Evaluation of the roles of these two factors is important in order to clarify the microscopic mechanism of deformation and, further, to derive a constitutive relationship which covers wide ranges of the strain rate and the temperature. Experimentally, the evaluation of the effect of the strain rate history has been made mostly with the strain rate change test, the measurement of the response of the flow stress to a sudden change in the strain rate. At very high strain rates, however, because of limitations in the time resolution capability, this type of test is difficult, and tests have been made mostly at strain rates below $2000 / \mathrm{s}$, except for the test utilising the flying plate technique for foil specimens. (1) This paper describes two types of strain rate change test conducted by the present authors' group in a higher strain rate range together with discussion on the constitutive relationship based upon the results of the above experiments.

Sakino and Shioiri (2) devised a new apparatus for the strain rate 
reduction test which has a high time resolution capability. Tests have been conducted for aluminium, copper, iron and niobium at strain rates up to $20000 / \mathrm{s}$. Besides, Shioiri et al. (3) showed that the attenuation of the ultrasonic pulse superimposed upon the dynamic plastic deformation gives the component of the strain rate sensitivity $(d \sigma / d \log \dot{c})$ due to the instantaneous strain rate. The above ultrasonic measurement can be regarded as a strain rate change test utilising a high frequency perturbation of the strain rate. Very recently, the ultrasonic measurements were made for aluminium and copper at strain rates up to $12000 / \mathrm{s}$ and $10000 / \mathrm{s}$, respectively.

\section{STRAIN RATE REDUCTION TEST}

Recently, Sakino and Shioiri (2) developed a new apparatus for the strain rate reduction test at very high strain rates. The apparatus is, as shown in Fig. 1, composed of three ma in parts, i.e., a projectile, a decelerator and a pressure bar for the stress measurement. The specimen attached at the end of the pressure bar with a thin grease film is directly compressed by the projectile. During the compression the projectile collides with the deceleretor and the velocity of the front of the projectile and, accordingly, the strain rate of the specimen are suddenly decreased. The details of the apparatus and the method of measurement were already reported in Ref.(2).

In this system, there are two problems which affect the time resolution capability. One is the quality of the strain rate change. The test on this point was made and it was shown that a well-controlled stepwise change in the velocity of the front surface of the projectile can be obtained. (2) The other is the time resolution capability of the flow stress measurement system which is affected by the dispersion of the elastic wave in the pressure bar and the frequency response of the strain gauge system including the electronic apparatus. By impacting upon the end surface of pressure bar with a bar of the same material and diameter, the response of the flow stress measurement system to a unit step input was obtained. Utilising the obtained response function, the deconvolution miethod was applied to the $\sigma-t$ data stored in the transient digital memory to obtain the real $\sigma-t$ relationship, and accordingly the load exerted by the specimen upon the pressure bar. (4) The resolution times of both the loading system and the stress measurement system are about $0.5 \mu \mathrm{sec}$.

A typical response of the flow stress for a sudden change in the strain rate is shown in Fig. 2. Denoting, as shown in Fig. 3 , the flow stress fall due to the strain rate reduction by $\Delta \sigma_{f}$ and the flow stress difference between two constant strain rate flows at the strain rates before and after the strain rate reduction by $\Delta \sigma_{\mathrm{d}}$, the ratio $\left(\Delta \sigma_{\mathrm{f}} / \Delta \sigma_{\mathrm{d}}\right)$ can be regarded as a measure of the dependency of the flow stress upon the instantaneous strain rate. In Fig. 4, the results for aluminium, copper, niobium and $0.01 \% \mathrm{C}$ iron are summarised in terms of

$\left(\Delta \sigma_{f} / \Delta \sigma_{d}\right)$. From the above results for typical FCC and BCC metals, it may be concluded that at very high strain rates, where in case of FCC metals the steep rise in the strain rate sensitivity $(\mathrm{d} \sigma / \mathrm{d} \log \dot{\varepsilon})$ appears, the instantaneous strain rate plays a dominant role in the strain rate dependency of the flow stress.

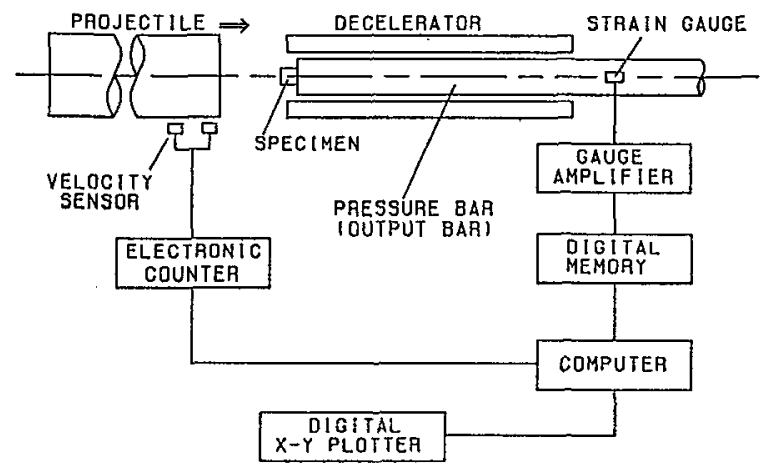

Fig. 1 Devised apparatus for strain rate reduction test 


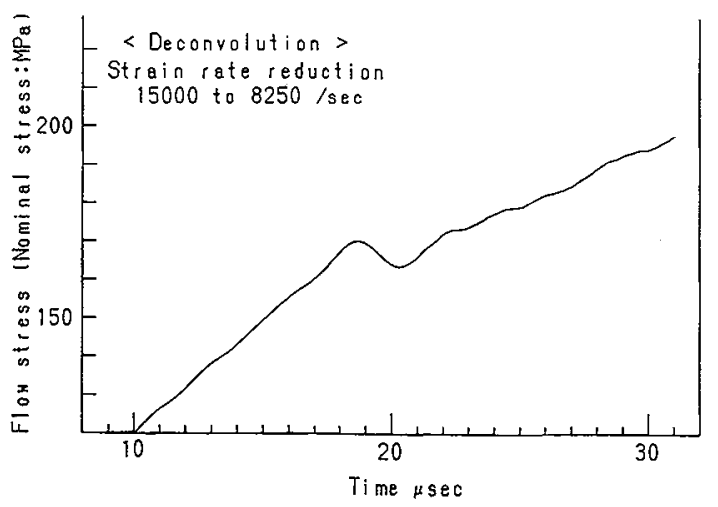

Fig. 2 Response of flow stress to sudden strain rate reduction (aluminium)

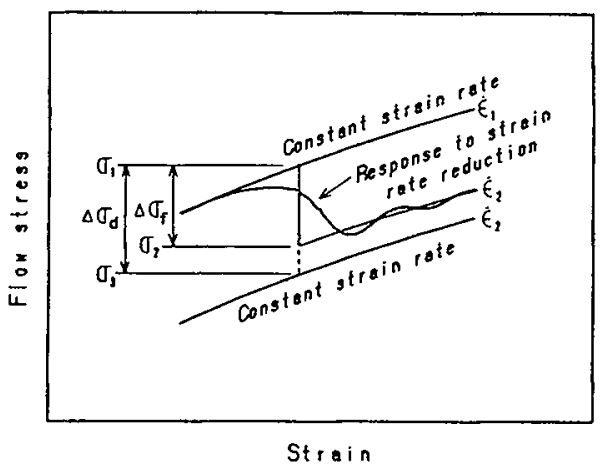

Fig. 3 Schema for definition of $\left(\Delta \sigma_{i} / \Delta \sigma_{d}\right)$

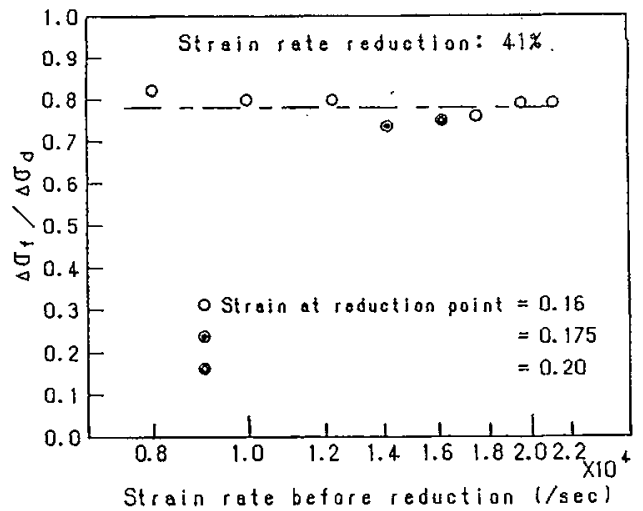

(a) aluminium

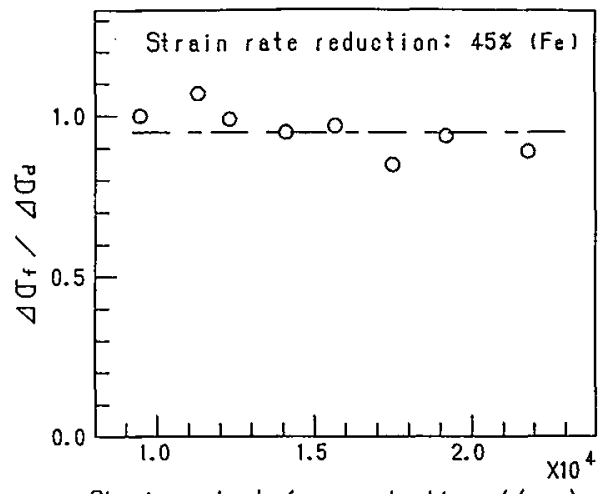

Strain rate before reduction (/sec)

(c) iron

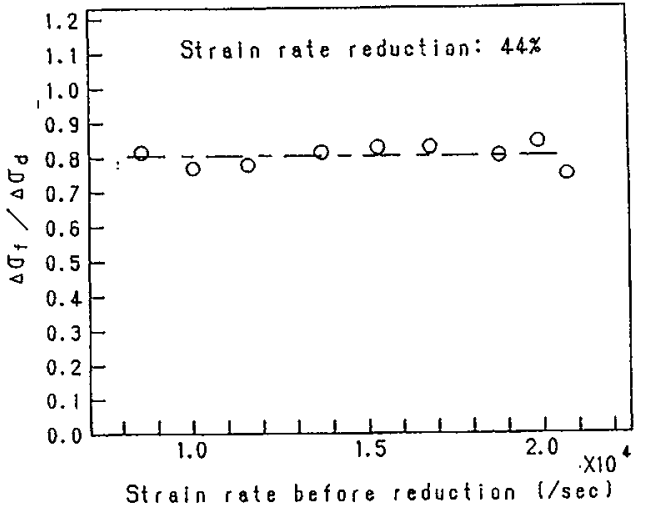

(b) copper

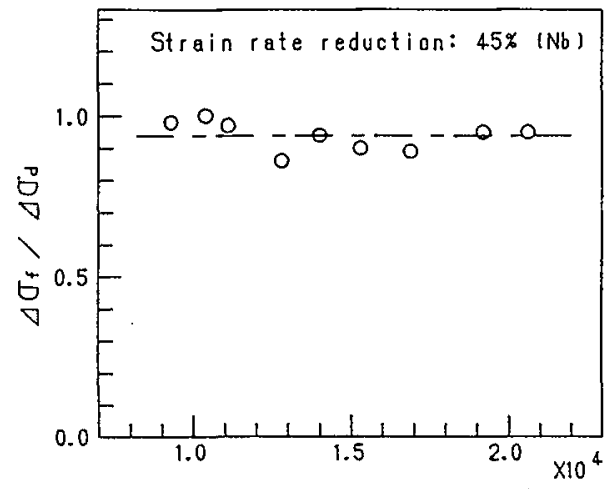

Strain rate before reduction (/sec)

(d) niobium

Fig.4 $\left(\Delta \sigma_{f} / \Delta \sigma_{d}\right)$ for aluminium, copper, iron and niobium 


\section{ULTRASONIC ATTENUATION METHOD}

Shioiri and Satoh tried the time resolved measurement of the attenuation of the ultrasonic pulse superimposed upon the dynamic plastic deformation. Microscopically, the attenuation data can give information on dislocations under dynamic plastic deformation. ${ }^{(5,6)}$ While, continuum-mechanically, the superposition of the ultrasonic wave upon the dynamic plastic deformation can be regarded as a strain rate change test utilising a high frequency perturbation in the strain rate, and the attenuation can be related to the dependency of the flow stress upon the instantaneous strain rate as

$$
(\mathrm{d} \sigma / \mathrm{d} \log \dot{\varepsilon})_{\mathrm{o}}=2 \dot{\varepsilon} \Omega \mathrm{G} /(\Delta \lambda) \mathrm{f}
$$

where $\sigma$ is the flow stress, $\dot{\varepsilon}$ the strain rate, $\Omega$ the orientation factor determined by the direction of the dynamic deformation and that of the propagation of the ultrasonic pulse, G the shearing modulus, $(\Delta \lambda)$ the attenuation caused by the dynamic deformation upon which the ultrasonic pulse is superimposed, $f$ is the ultrasonic frequency. (3)

The details of the experimental technique were reported in Ref. (3). The specimen is compressed dynamically with the standard split Hopkinson pressure bar method, and the ultrasonic pulse is sent at a right angle to the axis of the dynamic compression. In this case, assuming the Schmid factor of the active slip system of the dynamic compression to be $0.5, \Omega$ is given by

$$
\Omega=(3 \mathrm{E} / 32 \mathrm{G})(1-2 \nu) /\left(1-\nu^{2}\right)
$$

where $\mathbb{E}$ is the longitudinal modulus and $\nu$ is Poisson's ratio. (7)

Since, at very high strain rates, the attenuation of the ultrasonic pulse becomes very high and accordingly the received ultrasonic signal becomes very weak, the background noise in the receiving system causes a difficulty. In the present measurements, a special attention was paid to the suppression of the noise. As a result, the strain rate dependence of the attenuation at very high strain rates obtained in the present measurements differs a little from the results of the previous measurements reported in Ref. (3). The results of the present measurements for polycrystalline $5 \mathrm{~N}$ aluminium and $4 \mathrm{~N}$ copper are shown in Fig. 5. As was predicted in the previous work, (8) the attenuation has a maximum at a strain rate of about $5000 / \mathrm{s}$ and at higher strain rates it gradually decreases. In the previous measurements, ${ }^{(3)}$ the above maximum was not observed, but, at strain rates above about $5000 / \mathrm{s}$, the attenuation plotted against the strain rate was flat.

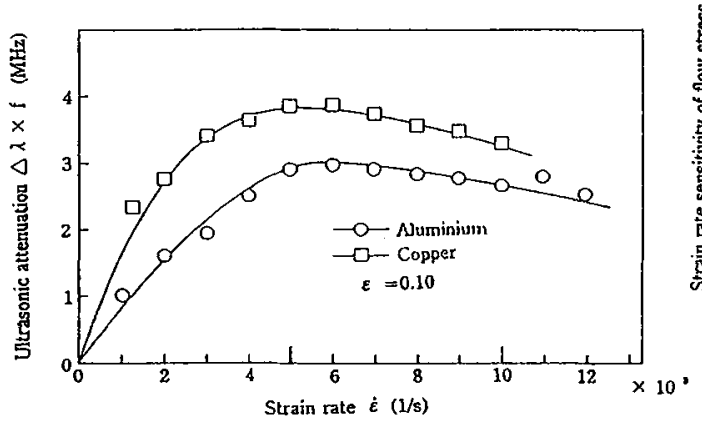

Fig. 5 Ultrasonic attenuation vs. strain rate (aluminium and copper)

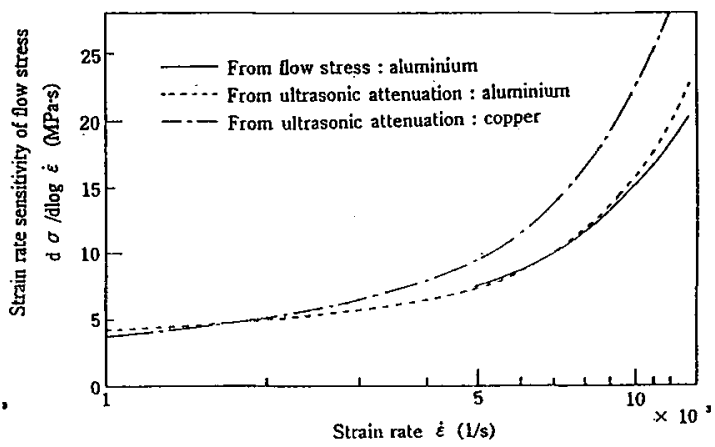

Fig. 6 Strain rate sensitivity of flow stress vs. strain rate 
Using Eqs. (1 and 2), the strain rate sensitivity of the flow stress $(\mathrm{d} \sigma / \mathrm{d} \log \dot{\varepsilon}$ ) was calculated from the attenuation data. The results are shown in Fig. 6. For comparison, $(\mathrm{d} \sigma / \mathrm{d} \log \dot{\varepsilon})$ calculated from the flow stress data are also shown. A close agreement is observed. If it is considered that (d $\sigma / d \log \dot{\varepsilon}$ ) calculated from the attenuation data does not include the effect of the strain rate history while $(\mathrm{d} \sigma / \mathrm{d} \log \varepsilon)$ calculated from the flow stress data does the effect of the strain rate history, it may be concluded that at least in the strain rate range in which the present ultrasonic measurements were conducted, the effect of the strain rate history upon the strain rate sensitivity $(d \sigma / d \log \dot{\varepsilon})$ is small and the effect of the instantaneous strain rate is dominant.

\section{DISCUSSION AND CONCLUSION}

As is shown in Section 2, the results of the strain rate reduction tesis for both FCC and Bcc metals conducted in the strain rate range from about 5000 to $20000 / \mathrm{s}$ indicate that the strain rate dependency of the flow stress is governed mainly by the instantaneous strain rate and the effect of the strain rate history is small. The same conclusion was drawn from the results of the ultrasonic measurements concerning the strain rate sensitivity of the flow stress (d $\sigma / \mathrm{d} \log \dot{\varepsilon})$ of the Fce metals at strain rates ranging from about 1000 to $10000 \% \mathrm{~s}$.

In most Fcc metals, at strain rates below about $5000 / \mathrm{s}, \sigma-\log \dot{\varepsilon}$ relationship is linear. While, at strain rates above about $5000 / \mathrm{s}, \sigma-\bar{\varepsilon}$ relationship becomes 1 inear. This transition appears on $\sigma-\log \dot{\varepsilon}$ diagram as the well-known steep rise of the flow stress at strain rates above about $5000 / \mathrm{s}$. Therefore, the so-called steep $r$ ise in the flow stress at very high strain rates is of qualitative nature rather than of quantitative nature. If the experimental results that the strain rate dependency of the flow stress is mainly due to the instantaneous strain rate are taken into account, the above transition in the relationship between $\sigma$ and $\dot{\varepsilon}$ may be reasonably attributed to the transition in the rate controlling mechanism of dislocation motion from the thermally assisted cutting of forest dislocations to the viscous drag, and the kinetic model presented in the previous work ${ }^{(5,6)}$ may be the basis for the constitutive relationship.

It is widely known that the strain rate and temperature dependencies of the flow stress of Bcc metals are large but no steep change in the gradient of $\sigma-\log \dot{\varepsilon}$ curve is observed. Figure 7 shows the resilt of measurements in the present work for $0.01 \%$ carbon iron at strain rates up to $30000 / \mathrm{s}$. From the microscopic point of view, the deformation of bcc metals is characterised by the high Peierls force. The deformation occurs mainly by the motion of the screw dislocations overcoming the high Peierls potential with the aid of the motion of the kink, and the deformation is rate-controlled by the rate of the formation of the kink pair. The kink pair is formed with the aid of the thermal activation, and accordingly it is widely accepted that the strain rate is expressed in the form of the Arrhenius equation

$$
\dot{\gamma}=\dot{\gamma}_{0} \exp \left[-\mathrm{E}(\tau) / \mathrm{k}{ }_{\mathrm{T}}\right] \text {, }
$$

where $\dot{\gamma}$ the shear strain rate, $\dot{\gamma}_{0}$ a constant with the dimension of the strain rate, $E(\tau)$ the activation energy for formation of the $k$ ink pair, $\tau$ the resolved shear stress, $k$ Boltzmann's constant, and $T$ is the absolute temperature. Aono et al. (') made measurements for single crystals of extremely high purity iron and 150atppm $C$ iron and confirmed that Eq. (3) holds. The measurements were made at low strain rates, but the temperature range covered very low temperature and $\mathrm{E}(\tau)$ was determined over a wide range of stress including the very high stress which is seen in the present work at very high strain rates. Assuming $\tau=0.5 \sigma$ and $\varepsilon=0.5 \gamma$, Eq. (3) is fitted to the experimental values in Fig. 7 using $E(\tau)$ deterained by Aono et al. for 150atppm $\mathrm{C}$ iron crystal. By taking $\log 0.5 \dot{\gamma}_{0}=5.36$, as is seen in Fig. 7 a good correlation is observed between the experimental flow stress and the 


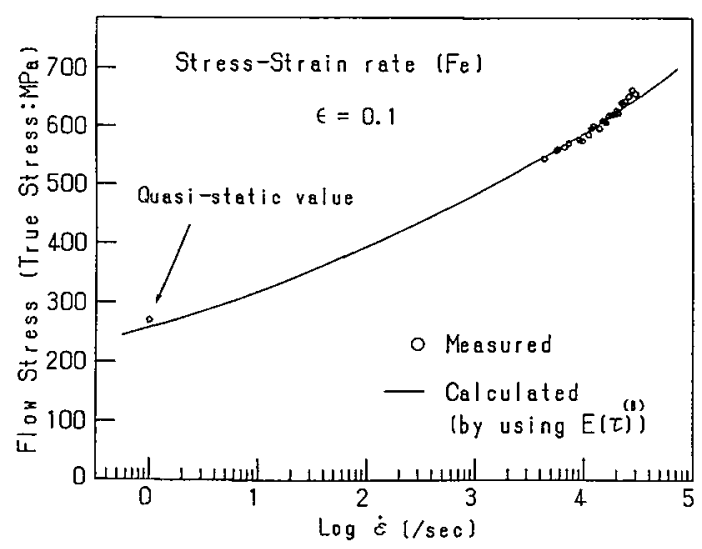

Fig. 7 Strain rate dependency of flow stress of iron: solid line is calculated using $E(\tau)$ of Aono. (9)

calculated curve. In the Arrhenius equation, generally speaking, the pre-exponential term (in the present case $\dot{\gamma}_{0}$ ) has a less importance compared with the exponential term; in $\sigma-10 \varepsilon=$ diagram, the shape of the curve is determined by the exponential term and by changing the pre-exponential term the curve moves along the horizontal axis without changing its shape. Therefore, boldly speaking, the strain rate dependency of the flow stress obtained in the present experiments is caused by the stress dependency of the rate of the kink pair formation, and accordingly is governed by the instantaneous strain rate. In fact, in the experimental results sisown in Fig. 4(c), $\left(\Delta \sigma_{f} / \Delta \sigma_{d}\right)$ is nearly $100 \%$. Further, it must be noted that the carbon content of 150 atppm is as high as about $70 \%$ of the saturation content for $\alpha$ iron but E $(\tau)$ obtained by Aono et al. for 150atppm C iron differs very little from that for extra pure iron. This means that, as far as $\alpha$ iron (ferrite) is concerned, the effect of the carbon content is small. In case of the low carbon steel for engineering use, however, the volume fraction of pearlite which is harder than ferrite, should be considered for deriving the constitutive relationship.

From the present study, it is concluded that, in both Fcc metals (aluminium and copper) and Bcc metals (iron and niobium), the strain rate dependency of the flow stress at strain rates up to about $20000 / \mathrm{s}$ is governed mainly by the instantaneous strain rate.

\section{REFERENCES}

(1) Tong, W. and Clifton, R.J., J. Mech. Phys. Solids, 40 (1992) 6, 1251-1294

(2) Sakino, K. and Shioiri, J., Trans. Jap. Soc. Mech. Engs., 58 (1.992) 553, A, $1703-1709$ (in Japanese)

(3) Shiojri, J., Imaizumi, H, and Muramatsu, T., J. Physique, IV (1991) C3, $177-183$.

(4) Sakino, K. and Shioiri, J., Trans. Jap. Soc. Mech. Engs., 59 (1993) 566, A, 2317-2322 (in Japanese)

(5) Shioiri,J, and Satoh, K., Inst. Phys. Conf. Ser., 70 (1984) 89-96

(6) Shioiri,J. and Satoh, K., J. Physique, 46 (1985) C5, 3-10

(7) Shioirj,J. and Satoh, K., Inst. Phys. Conf. Ser., 47 (1979) 121-129

(8) Shioiri,J., Impact Loading and Dynamic Behaviour of Materials (DGH Informationsgesellschaft, 1988) Vol.2, 807-814

(9) Aono, Y., Kuramoto, E. and Kitajima, K., Rep. Res. Inst. Appl. Mechanics, Kyushu University, XXIX (1981) 92, 127-193 